\title{
Optimization of Losses Joule in the Congolese Electrical Network Integrated with the Energy Pool of Central Africa in the PEAC Acronym
}

\author{
Mathurin Gogom*, Courad Onesime Tsahat Oboulhas, Nianga Apila, \\ Anedi Oko Ganongo, Désiré Lilonga-Boyenga
}

Laboratoire de Génie Electrique et Electronique, Ecole Nationale Supérieure Polytechnique, Université Marien Ngouabi, Brazzaville, Congo

Email: *mathuringogom@gmail.com

How to cite this paper: Gogom, M., Tsahat Oboulhas, C.O., Nianga Apila, Oko Ganongo, A. and Lilonga-Boyenga, D. (2022) Optimization of Losses Joule in the Congolese Electrical Network Integrated with the Energy Pool of Central Africa in the PEAC Acronym. Energy and Power Engineering, 14, 13-34.

https://doi.org/10.4236/epe.2022.141002

Received: November 8, 2021

Accepted: January 21, 2022

Published: January 24, 2022

Copyright $\odot 2022$ by author(s) and Scientific Research Publishing Inc. This work is licensed under the Creative Commons Attribution International License (CC BY 4.0).

http://creativecommons.org/licenses/by/4.0/

\section{(c) (i) Open Access}

\begin{abstract}
Joule losses in the power grids are a factor in the degradation of power grid equipment (lines and transformers), but also a shortfall for power companies, which must maximize their revenues. This is why in this article we present a study on the optimization of joule losses in a meshed electricity network interconnected to a very high voltage power line crossing Congolese territory for nearly one thousand five hundred (1500) kilometers. The value of interconnections no longer needs to be demonstrated in view of these technical, economic and social advantages. The object of this study is to assess the optimal node where the interconnection can be achieved which would cause fewer joule losses in the networks to be interconnected on this line. Indeed, it can have several possible nodes where the interconnection can be carried out, so it is necessary to simulate each configuration in order to evaluate the losses using the hybrid method including the genetic algorithm to provide different configurations and the Newton Raphson algorithm. Advanced integrating FACTS devices in this case STATCOM to perform load flow. The results are interesting because by injecting electrical energy to the network or to the line to the same selected, the joule losses are within the standards provided by the International Electrotechnical Commission.
\end{abstract}

\section{Keywords}

Interconnection, Joule Losses, Configuration, Genetic Algorithm, Newton Raphson Algorithm, FACTS and Load Flow

\section{Introduction}

Joule losses in electrical networks are not only a degradation factor, but also a 
shortfall for electricity companies. The standards require that these losses cannot exceed 3\% of the power consumed in the electrical transmission networks and $5 \%$ in the electrical distribution networks [1].

As part of the Central Africa Energy Pool PEAC acronym, several national electrical networks will be connected in order to extract or inject electrical energy. In view of the geographical position of certain countries, the transmission and interconnection line will cross a good part of their territory like the Congo. Consequently, the interconnection can generate as many Joule losses thus causing technical and economic inconvenience to the companies in charge if the location is poorly chosen. Thus, it is essential to choose an optimal location where the interconnection can be made to cause fewer joule losses.

Indeed, when the physical flows of electrical energy pass over long distances, the joule losses resulting from this transit are significant, because of the high resistances due to the length of the conductors and the current intensities which pass through them. To optimize these losses due to this transit, the choice of location to achieve the interconnection is essential.

In view of the problem of interconnection in this context, the joule losses should be optimized through an optimal choice of the interconnection node. To do this, we will use a hybrid algorithm: genetic algorithms and the advanced Newton Raphson algorithm using FACTS (Flexible Alterning Current Transfer Systems) [2] [3] [4] [5] and [6]. The genetic algorithms realize the possible configurations while the advanced Newton Raphson algorithm using FACTS performs the load flow calculation, of which the objective is to select an optimal configuration [2] [3] [4] [5] and [6]. This hybrid algorithm is transcribed in the Matlab environment and an application is made on the interconnection of the Congolese network to the PEAC.

The expected results of this study are the selection of an optimal configuration and the evaluation of the joule losses which would obey the standards provided by the International Electrotechnical Commission.

\section{Theoretical Study on Joule Losses}

When a line or transformer is traversed by electric current, there are losses of power and electrical energy which must be within the limits prescribed by the standards. In this paragraph, we will talk about the main losses.

\subsection{Line Losses}

The transport of electric current through a power line is subject to loss of power and energy. These losses are due to:

- The resistivity of the conductors causing the joule losses;

- The crown effect.

\subsubsection{Joule Losses}

They constitute the main component of transport losses. These losses are caused by the current flowing in the lines. Consider Figure 1 below; the power lost by 


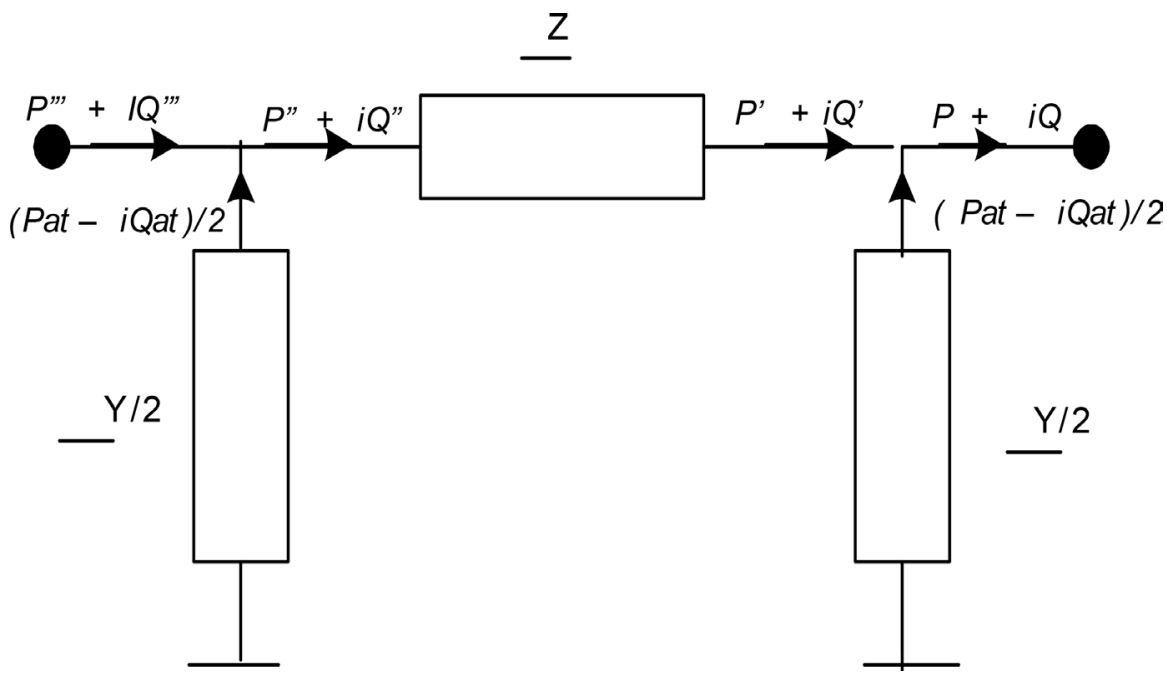

Figure 1. Model of a line describing the losses.

the Joule effect can be calculated in two ways [7] and [8]:

At the start of the line:

$$
\begin{gathered}
\Delta P_{l}=3 R_{l} I^{2}=3 R_{l}\left(I_{a}^{2}+I_{r}^{2}\right) \\
P^{\prime \prime}=\sqrt{3} U_{1} I \cos \varphi_{1}=\sqrt{3} U_{1} I_{a} \text { that is } I_{a}=\frac{P_{c}^{\prime \prime}}{\sqrt{3} U_{1}} \\
Q^{\prime \prime}=\sqrt{3} U_{1} I \cos \varphi_{1}=\sqrt{3} U_{1} I_{r} \text { that is } I_{r}=\frac{Q_{c}^{\prime \prime}}{\sqrt{3} U_{1}}
\end{gathered}
$$

So,

$$
\Delta P_{l}=R_{l} \frac{P_{c}^{\prime \prime 2}}{U_{1}^{2}}+R_{l} \frac{Q_{c}^{\prime 2}}{U_{1}^{2}}=R_{l} \frac{S_{c}^{\prime \prime 2}}{U_{1}^{2}}
$$

At the end of the line:

$$
\begin{gathered}
\Delta P_{l}=3 R_{l} I^{2}=3 R_{l}\left(I_{a}^{2}+I_{r}^{2}\right) \\
P_{c}^{\prime}=\sqrt{3} U_{2} I \cos \varphi_{2}=\sqrt{3} U_{1} I_{a} \text { that is } I_{a}=\frac{P_{c}^{\prime}}{\sqrt{3} U_{2}} \\
Q_{c}^{\prime}=\sqrt{3} U_{2} I \cos \varphi_{2}=\sqrt{3} U_{1} I_{r} \text { that is } I_{r}=\frac{Q_{c}^{\prime}}{\sqrt{3} U_{2}}
\end{gathered}
$$

So,

$$
\Delta P_{l}=R_{l} \frac{P_{c}^{\prime 2}}{U_{2}^{2}}+R_{l} \frac{Q_{c}^{\prime 2}}{U_{2}^{2}}=R_{l} \frac{S_{c}^{\prime 2}}{U_{2}^{2}}
$$

\subsubsection{Crown Losses}

When a wire is brought to a high electric potential, the field around it can become strong enough to cause ionization of molecules in the air. The ions thus formed are then entrained by the electrostatic force and tend to move along the field lines, which induces leaks. These losses are amplified in wet weather or by precipitation (snow, rain, etc.). The losses by corona effect depend on the ten- 
sion of the lines and the amount of precipitation. The study of corona losses is approached by taking into account the characteristics of transmission lines (circuit length and route by voltage level), the frequency of precipitation and experimental data. The losses due to the crown effect are given by the following formula:

$$
\Delta P_{c}=3 G V^{2}
$$

\subsection{Losses in the Transformer}

\subsubsection{Power Lost by Joule Effect}

They constitute the main component of transport losses. These losses are caused by the current flowing through the transformers. For a transformer operating in normal mode in Figure 2, the active power lost in it is determined as follows [7] and $[8]$ :

$$
\Delta P_{T}=3 R_{1} I_{1}^{2} \text { or } \Delta P_{T}=R_{2} I_{2}^{2}
$$

when the parameters are respectively reduced to primary or secondary. Consider the case where the parameters are reduced to primary,

$$
\begin{gathered}
\Delta P_{T}=3 R_{1} I_{1}^{2} \text { avec } \bar{I}_{1}=I_{1 a}-j I_{1 r}, \\
\Delta P_{T}=3 R_{1}\left(I_{1 a}^{2}+I_{1 r}^{2}\right)
\end{gathered}
$$

If we don't know $I_{1 a}$ et $I_{1 r}$, but rather $P_{1}, Q_{1}$ et $U_{1}$, so we can write:

$$
\begin{aligned}
& P_{1}=\sqrt{3} U_{1} I_{1} \cos \varphi_{1}=\sqrt{3} U_{1} I_{1 a} \text { that is } I_{1 a}=\frac{P_{1}}{\sqrt{3} U_{1}} \\
& Q_{1}=\sqrt{3} U_{1} I_{1} \sin \varphi_{1}=\sqrt{3} U_{1} I_{1 r} \text { that is } I_{1 r}=\frac{Q_{1}}{\sqrt{3} U_{1}}
\end{aligned}
$$

then

$$
\Delta P_{T}=R_{1} \frac{P_{1}^{2}}{U_{1}^{2}}+R_{1} \frac{Q_{1}^{2}}{U_{1}^{2}}=R_{1} \frac{S_{1}^{2}}{U_{1}^{2}}
$$

\subsubsection{Power Lost in Iron}

We call iron losses the sum of the losses by hysteresis and the losses by eddy current. The magnetization of the transformer sheets is the cause of the iron losses. It is given by the formula below:
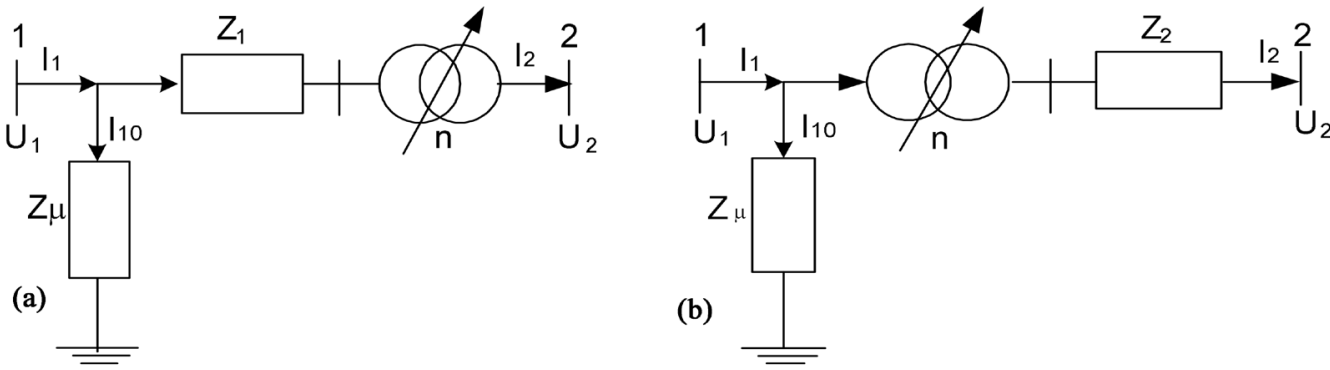

Figure 2. transformer model whose parameters are reduced: (a) to the primary and (b) to the secondary. 


$$
P_{10}=\frac{V^{2}}{R_{\mu}}
$$

\subsection{Allowable Loss Rate}

It is traditional to express losses as a rate. This rate allows comparisons between companies, and within a company comparisons between years. These rates have also allowed some authors to establish permissible rate ranges.

By definition, the optimal rate of technical losses is that which is reached when all the reinforcement works are profitable with regard to the economic parameters adopted (loss costs, reference costs of the works, discount rate, valuation of the quality of supply, ...) were completed on time.

The acceptable levels for energy losses, both for an entire electrical system and for each of these main components are defined by experts as follows [1]:

- For the entire electrical system (generation, transmission and distribution), $9 \%$ to $10 \%$ is adequate and $17 \%$ the maximum tolerable;

- For the transport network, $2 \%$ to $3 \%$ is suitable and $6 \%$ the maximum tolerable.

These rates are all based on the total energy injected into the transmission network.

\subsection{Hybrid Optimization Method}

The hybrid optimization method combines genetic algorithms and Newton Raphson's advanced method including FACTS.

\subsubsection{Genetic Algorithm}

This method is selected because of its speed of convergence and precision of the results compared to other metaheuristic methods [2] and [3]. In this subsection, we describe the different stages of genetic algorithms within the framework of our study.

\section{1) Initial population and coding}

The initial population which constitutes the set of network configurations is generated in a random manner. Its size results from a compromise between the calculation time, the number of variables to be optimized and the quality of the populations found. It is advisable to increase the size in order to promote the intensification and diversification of individuals or configurations.

The coding of the configurations is an important parameter of the method. The configurations are represented in the form of strings containing characters or (genes) of a determined alphabet. The encoding must be tailored to the problem in order to limit the size of the search space by producing valid solutions as often as possible when applying search operators. The representation must be such that the search operators are efficient in reproducing the sought solutions with a good probability.

In this work, we use binary encoding in which each solution is represented by a string of 0 or 1 called bit. The genetic algorithm often uses this representation 
when dealing with complex structures. The number of bits is equal to the number of nodes where the interconnection can be made. The string takes the character or (alphabet) 0 when the interconnection is not carried out at this node of the electrical network and 1 when it is carried out. Each character corresponds to a number of the desired node.

\section{2) Evaluation}

The evaluation is the most time-consuming part of the algorithm, because it needs the results of the load balancing calculation. Once the initial population is created, each individual (configuration) is evaluated against the optimization objective considered. For the search for an optimal interconnection node from which the losses are minimal, the evaluation consists of a calculation of the losses in the network by the Newton Raphson method in order to deduce the evaluation function. In our case, the evaluation function, called the fitness function is given by [3] [4] and [5]:

$$
f_{i t_{i}}=\frac{1}{p_{m}+\frac{x_{\text {cali }}-x_{\min }}{x_{\text {max }}-x_{\text {min }}} p_{c}}
$$

where $p_{m}$ is the probability of mutation, $p_{c}$ the probability of crossing, $x_{\text {cali }}$ the losses calculated for each configuration, $x_{\max }$ the upper limit of joule losses in networks and $x_{\min }$ the lower limit of joule losses in networks.

According to this formulation, the fitness function can take values between 0 and 10 for the best configurations, and greater than 10 for the less good. The population at a given time of the algorithm is called generation. Once the generation has been assessed, individuals are ranked according to the value of their fitness function.

\section{3) Selection}

The selection of individuals for the intermediate generation is carried out, in our case, by the draw on the biased roulette in which each individual has a proportional share to his fitness function. This selection technique allows good individuals to be part of the next generation, but it also avoids the premature convergence of the algorithm. It is necessary to maintain sufficient genetic diversity in the population to guarantee the genes that can be subsequently. Indeed, any individual can transmit genes to their descendants which, when combined with others, can be interesting.

\section{4) Crossing}

After selection, the crossing of two individuals to give two children can occur with a probability between 0.8 and 1 . In this research work, the multipoint crossing is applied. For this, a few points are drawn randomly, and between these points, the nodes of the two solutions (configurations) are exchanged. As mentioned in [2] and [3], two interconnections do not need to be made. An example of a multipoint crossing is shown in Figure 3.

5) Mutation

In our case, the mutations can take place on the characters of the two chains 
(the place of connection and the powers to be exchanged) representing a solution. The mutation effect results in a change of the value of the selected location. The new value is randomly drawn among the possible values. The mutation in several places of each of the two chains is illustrated in Figure 4.

A specific mutation probability is applied to each parameter:

$p_{\text {mes }}$ for interconnection locations;

$p_{m V}$ for the set point values of the exchanged powers.

These probabilities vary over generations. They increase to promote diversification when the population tends to be represented by only a few dominant individuals. The mutation probability can be between 0.01 and 0.2 . The general functioning of the genetic algorithms is given in Figure 5 [2] and [5].

\subsubsection{Advanced Newton-Raphson Method}

Advanced Newton-Raphson method is the load balancing calculation performed by including Statcom controllers. This method consists in solving the system of equations at the nodes of the electrical network, given by [2] [3] [4] [5] and [6]:

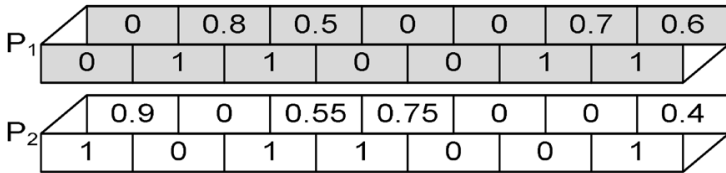

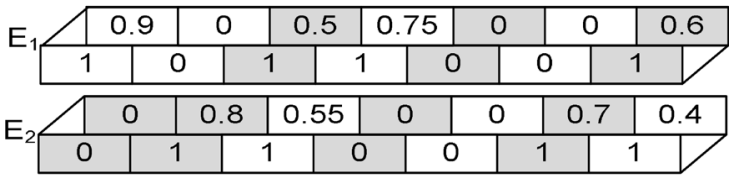

Figure 3. Multipoint crossing of both parents.

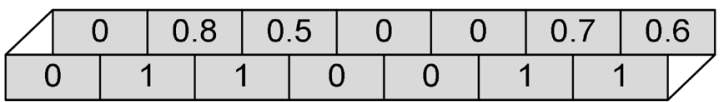

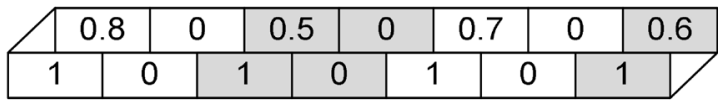

Figure 4. character mutation of two strings.

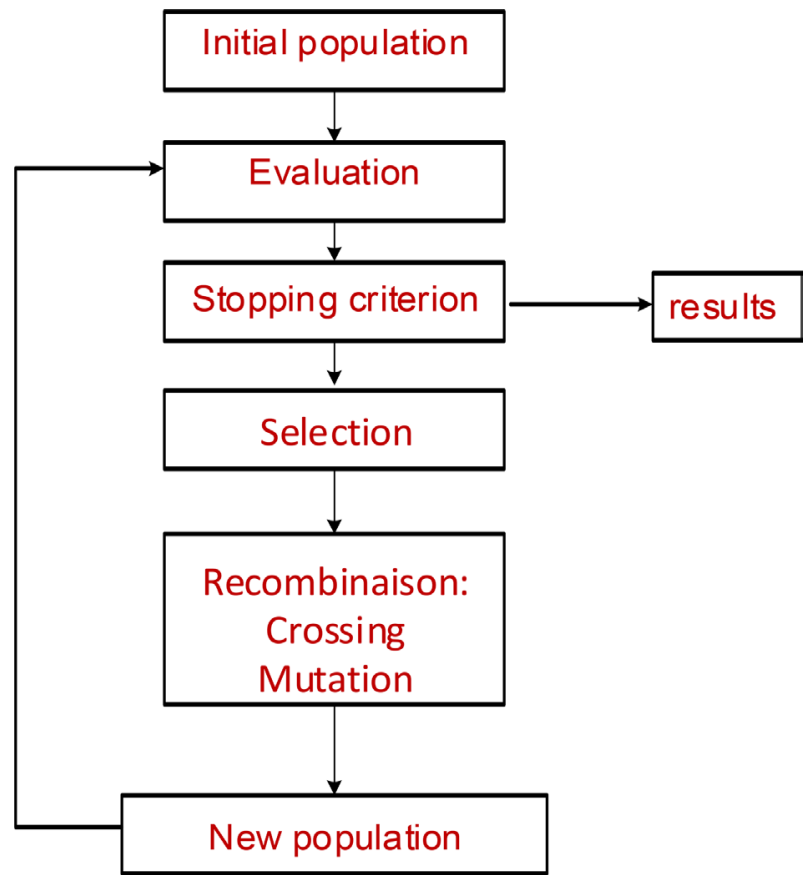

Figure 5. How genetic algorithms work. 


$$
\left\{\begin{array}{l}
P_{i}=Y_{i i} V_{i}^{2} \cos \left(\propto_{i i}\right)+V_{i} \sum_{k \neq 1}^{n} Y_{i k} V_{k} \cos \left(\varphi_{i}-\varphi_{k}-\alpha_{i k}\right) \\
Q_{i}=Y_{i i} V_{i}^{2} \sin \left(\propto_{i i}\right)+V_{i} \sum_{k=1}^{n} Y_{i k} V_{k} \sin \left(\varphi_{i}-\varphi_{k}-\alpha_{i k}\right)
\end{array}\right.
$$

This system is linearized and transcribed in the form of a matrix equation to have voltage modules and phases at the nodes of the electrical network. Once these voltage modules and phases have been obtained, the losses in the network are deduced from them using the nodes method. For this, the power transit equations are established in order to deduce the losses [2] [3] [4] [5] and [6]:

$$
\begin{aligned}
& P_{i k}=G_{i k}^{\prime} V_{i}^{2}-G_{i k} V_{i} V_{k} \cos \left(\theta_{i}-\theta_{k}\right)+B_{i k} V_{i} V_{k} \sin \left(\theta_{i}-\theta_{k}\right) \\
& Q_{i k}=B_{i k}^{\prime} V_{i}^{2}-G_{i k} V_{i} V_{k} \sin \left(\theta_{i}-\theta_{k}\right)-B_{i k} V_{i} V_{k} \cos \left(\theta_{i}-\theta_{k}\right) \\
& P_{k i}=G_{i k}^{\prime} V_{k}^{2}-G_{i k} V_{i} V_{k} \cos \left(\theta_{k}-\theta_{i}\right)+B_{i k} V_{i} V_{k} \sin \left(\theta_{k}-\theta_{i}\right) \\
& Q_{k i}=B_{i k}^{\prime} V_{k}^{2}-G_{i k} V_{i} V_{k} \sin \left(\theta_{k}-\theta_{i}\right)-B_{i k} V_{i} V_{k} \cos \left(\theta_{k}-\theta_{i}\right) \\
& \Delta P_{i k}=P_{i k}+P_{k i}=G_{i k}^{\prime}\left(V_{i}^{2}+V_{k}^{2}\right)-2 G_{i k} V_{i} V_{k} \cos \left(\theta_{i}-\theta_{k}\right) \\
& \Delta Q_{i k}=Q_{i k}+Q_{k i}=B_{i k}^{\prime}\left(V_{i}^{2}+V_{k}^{2}\right)-2 B_{i k} V_{i} V_{k} \cos \left(\theta_{i}-\theta_{k}\right)
\end{aligned}
$$

where the systems of Equations (3) and (4) are respectively the power transits seen from node $i$ and node $k$, and the system of Equation (5) reflects the losses in the network.

\subsection{Formulation of the Hybrid Optimization Problem}

In this work, we are looking for one of the probable nodes to achieve the interconnection that would cause the minimum Joule losses when the Congolese electrical network is perfectly regulated in voltage [5]. To do this, the objective function is formulated in order to minimize joule losses in the electrical network. The equality constraints are attached (the power equations at the nodes which must obey Kirchhoff's laws) and the inequality constraints are also attached:

- The tensions at the nodes must not deviate sufficiently from the reference values;

- Statcom generators and controllers must be operated close to their operating limits;

- Power transits in the lines must be close to thermal limits.

Thus, the hybrid optimization problem can be formulated by minimizing $f(X, U)$ to deduce the best fitness function $f_{i t_{i}}$ and take into account the following constraints:

$$
\left\{\begin{array}{l}
g(X, U)=0 \\
h(X, U) \leq 0
\end{array}\right.
$$

where $X$ is the state vector of the electrical network (modules and voltage phases at the nodes), $U$ the vector representing the variables of the Statcom controllers and the possible auxiliary variables, all considered as state variables and $f(X, U)$ 
the objective function, representing the joule losses in the electrical network, determined by the method of nodes. Thus, the fitness function given by relation (12) allows to evaluate and select necessary individuals for the recombination.

$$
f_{i t_{i}}=\frac{1}{p_{m}+\frac{f(X, U)_{\text {cali }}-f(X, U)_{\min }}{f(X, U)_{\text {max }}-f(X, U)_{\text {min }}} p_{c}}
$$

The relation $g(X, U)$ represents the equality constraints, corresponding to the power injection equations including those of Statcom and $h(X, U)$ the inequality constraints, reflecting the limitations on the equipment in service (generators, lines and Statcom):

- For generators, these limits are expressed by:

$$
Q_{i}^{\min } \leq Q_{i}(V, U) \leq Q_{i}^{\max }
$$

Où

$$
\begin{aligned}
& Q_{i}^{\min }-Q_{i}(V, U) \leq 0 ; \\
& Q_{i}(V, U)-Q_{i}^{\max } \leq 0 ;
\end{aligned}
$$

where $Q_{i}$ is a function of the modules and voltage phases at the $i^{\text {th }}$ node and all neighboring nodes. If at the end of the calculation, or during it, the production $Q_{i}$ exceeds the upper bound $Q_{i}^{\max }$, we impose:

$$
Q_{i}(V, U)-Q_{i}^{\max }=0
$$

Similarly, if the production exceeds the lower b $Q_{i}^{\min }$, we impose:

$$
Q_{i}^{\min }-Q_{i}(V, U)=0
$$

In both cases, the node of type PV becomes PQ.

- For lines, power flows should not exceed $90 \%$ of their respective transfer capability. For each row, the following inequalities are valid

$$
\begin{gathered}
S_{i k} \leq 0.9 S_{i k}^{\max }+\epsilon_{i k}, \quad 0 \leq \epsilon_{i k} \\
S_{i k} \leq S_{i k}^{\max }+\gamma_{i k}, 0 \leq \gamma_{i k}
\end{gathered}
$$

where the quantity $S_{i k}$ is the apparent power across the line $i k$ and $\epsilon_{i k}$ and $\gamma_{i k}$ the non-zero deviation variables if the initial constraints are not respected.

- For nodes, these are $V_{i}$ voltage, as soft constraints. These voltages $V_{i}$ are imposed to be around the reference value:

$$
V_{i}^{\min } \leq V_{i}^{\text {ref }} \leq V_{i}^{\max }
$$

$V_{i}^{\min }=0.95 V_{i}^{\text {ref }}$ is the minimum acceptable value of the voltage at node $i$; $V_{i}^{\max }=1.05 V_{i}^{\text {ref }}$ is the maximum acceptable value of the voltage at node $i$.

For the static reactive power compensator, the reactive power $Q_{\text {SтAтсом }}$ can take the values in the range:

$$
Q_{C \max } \leq Q_{\text {STATCOM }} \leq Q_{L \max }
$$

The operating principle of the hybrid optimization method is given by the algorithm shown in Figure 6 [6]. 


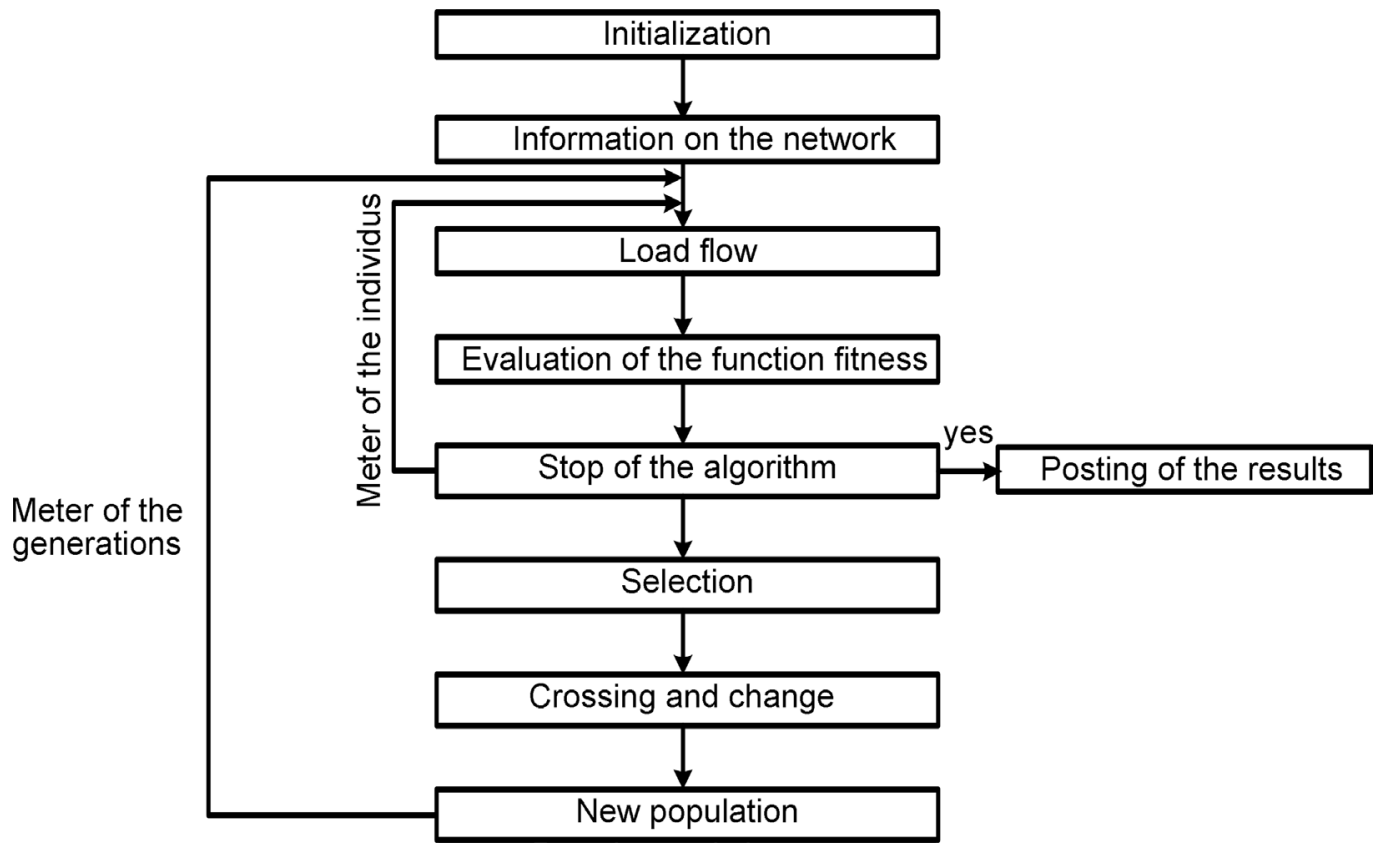

Figure 6. How the hybrid optimization algorithm works.

\section{Application to the Congolese Network Integratedin to the PEAC}

\subsection{Network Characteristics}

The integration of the Congolese electricity network into the PEAC will be carried out according to Figure A1. For this purpose, four connection points can be envisaged at $400 \mathrm{kV}$ (red line shown in Figure A2) [9] [10] and [11]:

- Node 8 in Ouesso (the country's second economic hub) in the north-west of the country is the first point of interconnection of the Congolese network to the PEAC.

This connection has three departures (first departure to supply the locality of Ouesso, second departure to Gabon, Cameroon, Nigeria and other countries and the third departure to RCA and Tchad). At the same time, it could constitute a connection point for the Chollet hydroelectric power station on the border with Cameroon, currently under study with an estimated power of $900 \mathrm{MW}$;

- Node 3 in Oyo, one of the economic hubs of the Republic of Congo, characterized by high consumption of electrical energy;

- Node 12 in Brazzaville, the political capital of Congo, constitutes the third point of interconnection to the PEAC;

- Node 37 in Pointe Noire, the most important economic hub in the country, represents the fourth interconnection point at PEAC.

This connection point has two purposes: first to guarantee the supply of this industrial zone with electrical energy and secondly to allow the future connection of the Sounda hydroelectric power station with an estimated power of 1200 MW under study. This site is located approximately at $75 \mathrm{~km}$ from Pointe-Noire by bird flight. The $400 \mathrm{kV}$ line that crosses the Congo is approximately $1200 \mathrm{~km}$ 
long in bird flight.

\subsection{Modelization}

\subsubsection{Modeling of the Interconnected Network}

Certain electrical networks have particular topologies or configurations, characterized by very varied operating voltages, in particular $400 \mathrm{kV} ; 220 \mathrm{kV} ; 110 \mathrm{kV}$ and $30 \mathrm{kV}$ which are the output voltages of the transformers.

Outside the lines whose modeling is simple, that of transformer swath two and three windings is complex. Transformers with two windings will be modeled as lines, while those with three windings will be modeled as two lines supplying two departures [6].

The $Z$ impedances and admittances of the transmission lines are determined such that:

$$
\begin{aligned}
& \underline{Z}=\underline{z}_{0} \cdot l=\left(r_{0}+i x_{0}\right) \cdot l \\
& \underline{Y}=\underline{y}_{0} \cdot l=\left(g_{0}+i b_{0}\right) \cdot l
\end{aligned}
$$

where $r_{0}$ and $x_{0}$ are the linear resistance and reactance of the transmission line, respectively; $g_{0}$ and $b_{0}$ the linear conductance and susceptance of the transmission line and $l$ the length of the transmission line.

The $Z$ impedances of the transformers, for their part, are determined such as:

- Transformers with two windings:

$$
\begin{gathered}
Z=\frac{U_{n c c} \% U_{n}}{100 \sqrt{3} I_{n}} \text { that is } \underline{Z}=R+i X \\
\text { With } R=Z \cos \varphi_{T} ; \quad X=Z \sin \varphi_{T} \text { and } \varphi_{T}=\tan ^{-1} \frac{X}{R}
\end{gathered}
$$

where $R$ and $X$ are the resistance and the leakage reactance of the transformer, respectively; $U_{n c c} \%$ the short-circuit voltage as a percentage ; $U_{n}$ nominal voltage and $I_{n}$ the nominal current intensity.

- Transformers with three windings:

$$
Z_{12}=\frac{U_{12 n c c} \% U_{1 n}}{100 \sqrt{3} I_{1 n}} ; Z_{13}=\frac{U_{13 n c c} \% U_{1 n}}{100 \sqrt{3} I_{1 n}} \text { et } Z_{23}=\frac{U_{23 n c c} \% U_{2 n}}{100 \sqrt{3} I_{2 n}}
$$

Then, we deduce:

$$
\begin{gathered}
R_{12}=Z_{12} \cos \varphi_{12} ; R_{13}=Z_{13} \cos \varphi_{13} \text { et } R_{23}=Z_{23} \cos \varphi_{23} \\
X_{12}=Z_{12} \sin \varphi_{12} ; X_{13}=Z_{13} \sin \varphi_{13} \text { et } X_{23}=Z_{22} \sin \varphi_{23} \\
\text { With } \varphi_{12}=\varphi_{13}=\varphi_{23}=\varphi=\tan ^{-1} \frac{X_{12}}{R_{12}}
\end{gathered}
$$

The base quantities calculated by the formulas below are summarized in Table below:

$$
Z_{B}=\frac{U_{B}^{2}}{S_{B}} \text { et } Y_{B}=\frac{1}{Z_{B}}
$$




\begin{tabular}{ccccc}
\hline & $S_{B}(\mathrm{MVA})$ & $U_{B}(\mathrm{KV})$ & $Z_{B}(\Omega)$ & $Y_{B}\left(\Omega^{-1}\right)$ \\
\hline 1 & 100 & 400 & 1600 & $0.625 \times 10^{-3}$ \\
2 & 100 & 220 & 484 & $2.066 \times 10^{-3}$ \\
3 & 100 & 110 & 121 & $0.826 \times 10^{-3}$ \\
4 & 100 & 30 & 9 & $111.11 \times 10^{-3}$ \\
\hline
\end{tabular}

Then, for each quantity, one will calculate its value in pu according to the formula below:

$$
\text { pu value }=\frac{\text { Real Value }}{\text { base value }}
$$

\subsubsection{Statcom Modeling}

STATCOM can be modeled by the simplified circuit of the control and compensation system in Figure 7. The modeling of this circuit is based on the following simplifying assumptions [12] [13] [14] and [15]:

- All switches are assumed to be ideal;

- The three voltages of the AC source are balanced;

- All voltage drops in STATCOM are represented by resistor $r_{p}$;

- Harmonics caused by the opening and closing action of switches are neglected;

- The leakage inductance of the shunt transformer is represented by the inductance $L_{p}$.

The STATCOM device controls:

- The injected voltage $V_{p}$ in phase with the voltage $V_{r}$ of the line;

- The voltage phase or the transport angle.

The main purpose of these two operating modes is to control the reactive power passing through the line. The dynamic equations of Statcom are obtained by applying the KIRCHHOFF law relating to the three phases [12] [13] [14] [15]:

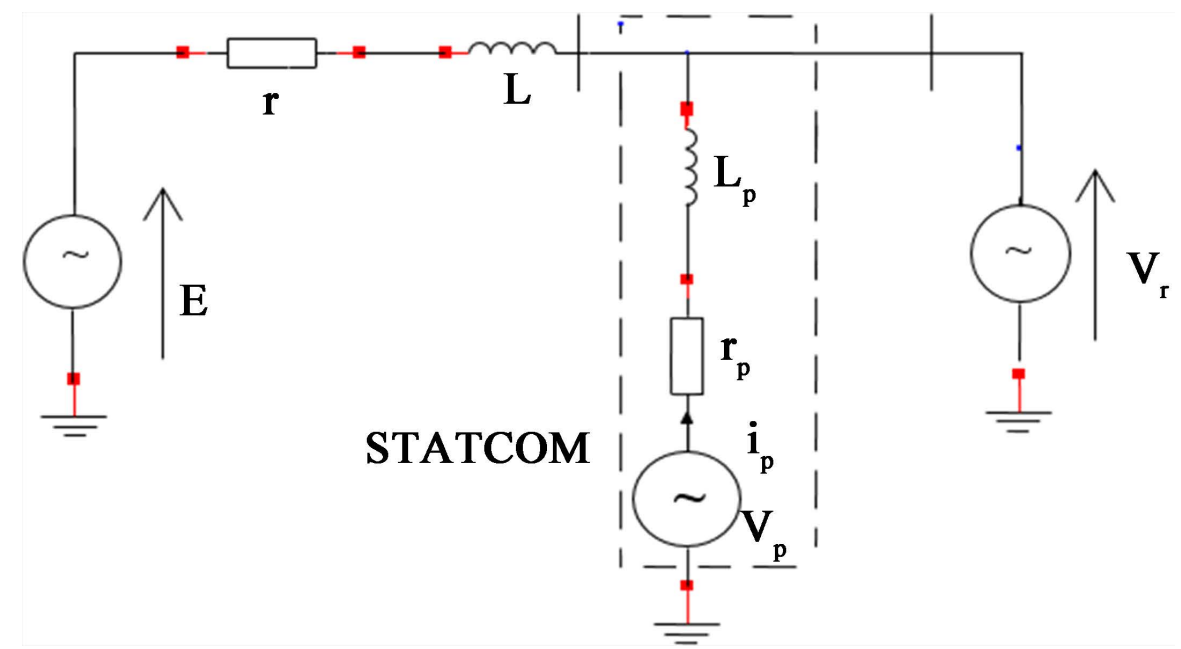

Figure 7. STATCOM model. 


$$
\left\{\begin{array}{l}
\frac{\mathrm{d} i_{a}}{\mathrm{~d} t}=-\frac{r}{L} i_{a}+\frac{1}{L}\left(V_{a}-V_{c a}-V_{r a}\right) \\
\frac{\mathrm{d} i_{b}}{\mathrm{~d} t}=-\frac{r_{p}}{L_{p}} i_{p b}+\frac{1}{L_{p}}\left(V_{p b}-V_{c b}-V_{r b}\right) \\
\frac{\mathrm{d} i_{c}}{\mathrm{~d} t}=-\frac{r_{p}}{L_{p}} i_{p c}+\frac{1}{L_{p}}\left(V_{p c}-V_{c c}-V_{r c}\right)
\end{array}\right.
$$

where $i_{, a b c}$ are the Statcom currents, $V_{, a b c}$ are the voltages generated by the inverter, $r$ and $L$ are the resistance and inductance of the Statcom respectively.

The system of Equation (15) can be rewritten in the matrix form (16):

$$
\left[\begin{array}{l}
V_{p a} \\
V_{p b} \\
V_{p c}
\end{array}\right]=\left[\begin{array}{ccc}
r_{p}+s \cdot L_{p} & 0 & 0 \\
0 & r_{p}+s \cdot L_{p} & 0 \\
0 & 0 & r_{p}+s \cdot L_{p}
\end{array}\right]\left[\begin{array}{c}
i_{p a} \\
i_{p b} \\
i_{p c}
\end{array}\right]+\left[\begin{array}{l}
V_{c a}+V_{r a} \\
V_{c b}+V_{r b} \\
V_{c c}+V_{r c}
\end{array}\right]
$$

Of which $i_{p a}, i_{p b}$ and $i_{p c}$ represent the shunt currents, moreover $V_{p a}$, $V_{p b}$ and $V_{p c}$ are the voltages generated by the inverter. In matrix form the system (15) becomes:

$$
\frac{\mathrm{d}}{\mathrm{d} t}\left[\begin{array}{l}
i_{p a} \\
i_{p b} \\
i_{p c}
\end{array}\right]=\left[\begin{array}{ccc}
-r_{p} / L_{p} & 0 & 0 \\
0 & -r_{p} / L_{p} & 0 \\
0 & 0 & -r_{p} / L_{p}
\end{array}\right]\left[\begin{array}{l}
i_{p a} \\
i_{p b} \\
i_{p c}
\end{array}\right]+\frac{1}{L_{p}}\left[\begin{array}{c}
V_{c a}+V_{r a} \\
V_{c b}+V_{r b} \\
V_{c c}+V_{r c}
\end{array}\right]
$$

\subsection{Simulations, Results and Discussion}

We simulate the Congolese electricity network interconnected to the PEAC on the basis of Equations (12) to (15). These equations are implemented in the Matlab environment. At the end of this simulation, the program returns the results with the mention "good configuration found" when the objective is reached and the constraints respected on the one hand, and "no solution found" when the objective is not. reached and/or when the constraints are not respected. Ultimately, the ideal interconnection node found is the one from which losses are minimal. The simulation results obtained when the Congolese network absorbs the electrical energy from the PEAC have selected node 12 as the interconnection point and the voltage modules and phases, as well as the injected and absorbed powers are presented in Table A1 and Table A2 in Annex 2. However, the simulation results obtained when the Congolese network injects electrical energy into the PEAC are shown in Table A3 and Table A4 in appendix 2. The results of simulations, when the Congolese network absorbs electrical energy from the PEAC, shown in Table A1 and Table A2 in the appendix show:

- That among the four (4) probable interconnection nodes, node 12 is selected as the interconnection node of the Congolese network to the PEAC, because at this node the joule losses in the Congolese network are equal to $0.22136 \mathrm{pu}$ when it is perfectly compensated.

- That to guarantee the national electricity supply (except rural areas), a quantity of approximately 11.7875 pu including the joule losses in the network is 
required, for a national production of $10.56 \mathrm{pu}$.

So, despite the project to build the hydroelectric dam at Chollet with an installed capacity of $3 \mathrm{pu}$, the Congo's share, it will still have an energy deficit; therefore it will be able to import $1.25 \mathrm{pu}$ from node 12 .

However, the results of simulations, when the Congolese network injects electrical energy into the PEAC, reported in Table A3 and Table A4 in appendix 2 show:

- That among the four (4) probable interconnection nodes, node 12 is always selected as the ideal interconnection node of the Congolese network to the PEAC, because at this node the joule losses in the Congolese network are equal to $1.35814871 \mathrm{pu}$ when it is perfectly compensated;

- That to guarantee the national electricity supply and ensure the injection of electric energy to the PEAC, a national production of $22.56 \mathrm{pu}$ is needed which can be obtained thanks to the construction of the hydroelectric dam of Sounda with a capacity of installed of $12 \mathrm{pu}$, and therefore the Congo will be able to export $10.7725 \mathrm{pu}$.

\section{Conclusions}

The selection of the interconnection node of the Congolese electricity grid at the PEAC was the subject of our study. It was a question of examining the four (4) possible configurations by performing a load distribution calculation integrating STATCOM.

Thus, node 12 was selected in both cases:

- When the Congolese electricity network receives power of $1.25 \mathrm{pu}$ from the PEAC, the joule losses are equal to $0.22136 \mathrm{pu}$, i.e. a rate of $1.62 \%<3 \%$, unlike nodes 3, 8 and 37 which respectively cause of losses of $5.75 \%, 6.3 \%$ and $4.81 \%$;

- When the Congolese electricity network injects a power of $10.7725 \mathrm{pu}$ to the PEAC, the joule losses are equal to $1.35814871 \mathrm{pu}$, i.e. a rate of $2.97 \%<3 \%$, unlike nodes 3,8 and 37 which respectively cause losses of $6.35 \%, 7.57 \%$ and $5.61 \%$.

In sum, we note that in one or the other case, the joule losses in the entire Congolese power grid are within the norm.

\section{Conflicts of Interest}

The authors declare no conflicts of interest regarding the publication of this paper.

\section{References}

[1] Prisme (2001) Contrôle des pertes non techniques d'électricité. Institut de l'énergie et de l'environnement de la Francophonie (IEPF). Fiche technique No. 8.

[2] StéphaneGerbex (2003) Metaheuristiques Appliquees Au Placement Optimal De Dispositifs Facts dans un Réseau Electrique. Thèse de doctorat No. 2742. EPFL.

[3] Acha, E., Fuerte-Esquivel, C.R., Ambriz-Perez, H. and Angeles-Camacho, C. (2005) 
FACTS: Modelling and Simulation in Power Network. John Wiley \& Sons Ltd., Hoboken. https://doi.org/10.1002/0470020164

[4] Cheukem, A. and Ngundam, J.M. (2009) Implementation of FACTS Devices in Electrical Power System for Available Transmission Capability Enhancement. International Journal of Numerical Methods and Applications, 1, 71-86.

[5] Srinivas, M. and Patnaik, L.M. (1994) Genetic Algorithms: A Survey. Computer, 24, 17-26. https://doi.org/10.1109/2.294849

[6] Gogom, M., Mimiesse, M., Nguimbi, G. and Lilonga-Boyenga, D. (2018) Improving Availability of Transit Capacity by the Hybrid Optimization Method. Journal of Scientific and Engineering Research, 5, 276-288.

[7] Sabonnadière, J.-C. and Hadjsaïd, N. (2007) Lignes et réseaux électriques. Lavoisier.

[8] Pal Barret, J., Bornard, P. and Mayer, B. (1997) Simulation des réseaux électriques. Editions EYROLLES.

[9] PA Consulting Group (USAID) (2005) Première Etude du Schéma Directeur pour l'Afrique Centrale.

[10] Direction Générale de l'Energie (2006) Schéma Directeur de Développement Industriel: Secteur Electricité. Ministère de l'Energie et de l'Hydraulique.

[11] Conseil Mondial de l'Energie (CME) (2008) Rapport sur l'Atelier de Haut Niveau du CME sur le Financement des Projets Hydroélectriques INGA, Tenu à Londres, le 21-22 avril 2008.

[12] Benras Med Amine, Larouisouleymane. Utilisation d'un dispositif STATCOM pour l'amélioration du transit de puissance d'un réseau de transport d'énergie alternatif, Mémoire de Master, 2015, Université KasdiMerbahOurgla, Algerie.

[13] Salim, H., et al. (2009) The Use of FACTS Devices in Disturbed Power System Modelling, Interface, and Case Study. International Journal of Computer and Electrical Engineering, 1, 56-60. https://doi.org/10.7763/IJCEE.2009.V1.9

[14] Hassan, H.A., Osman, Z.H. and El-Aziz Lasheen, A. (2014) Sizing of STATCOM to Enhance Voltage Stability of Power Systems for Normal and Contingency Cases. Smart Grid and Renewable Energy, 5, 8-18. https://doi.org/10.4236/sgre.2014.51002

[15] Ilango, R. and Raja, S. (2016) Fault Location Method for STATCOM Connected Transmission Lines Using CCM. Circuits and Systems, 7, 3131-3141. https://doi.org/10.4236/cs.2016.710266 


\section{Annex 1: Congolese electricity grid data}

We present here in Figure A1 the electrical map of Congo and in Figure A2 the Congolese electrical network integrated into the PEAC.

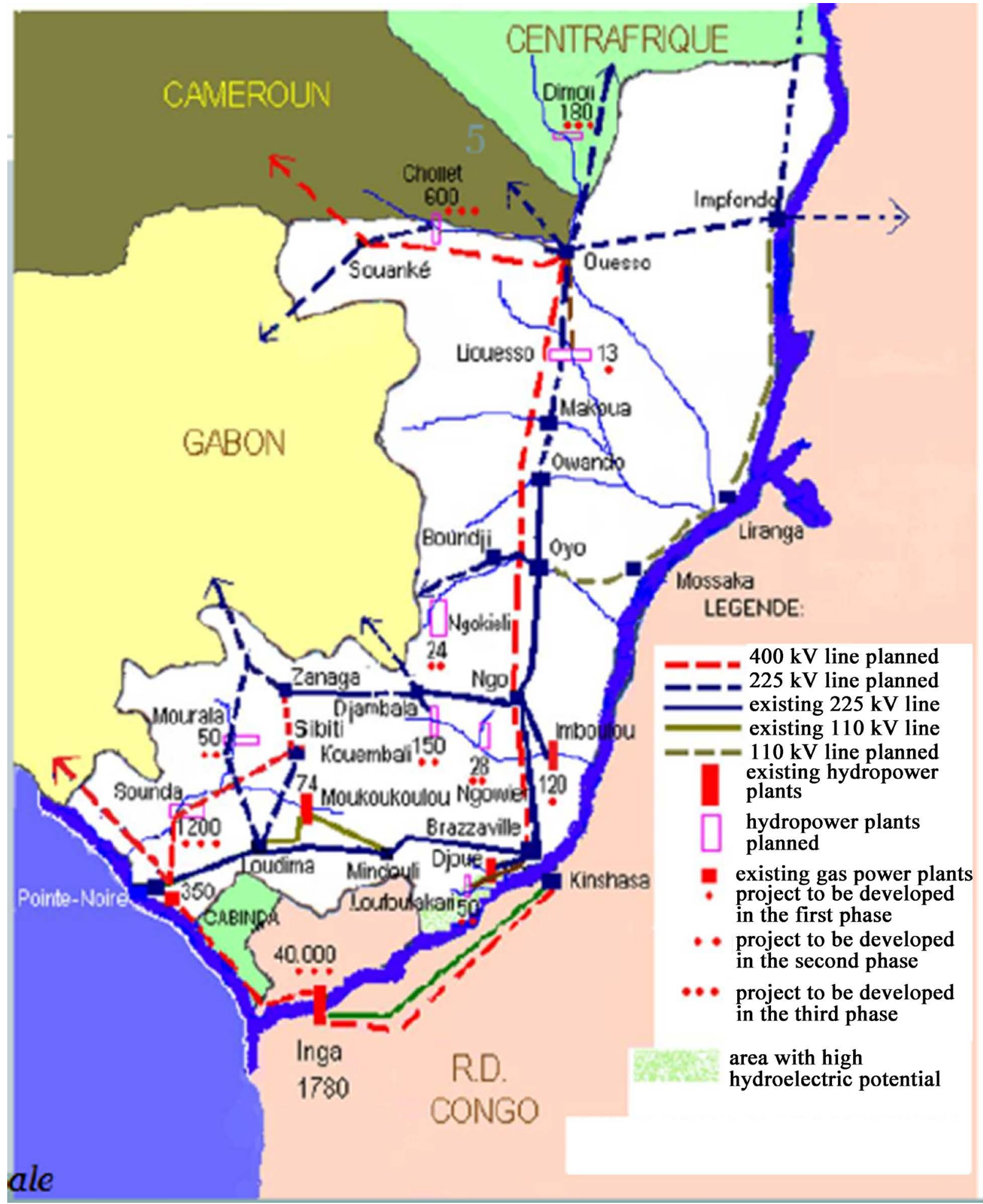

Figure A1. Congo Electric Map. 


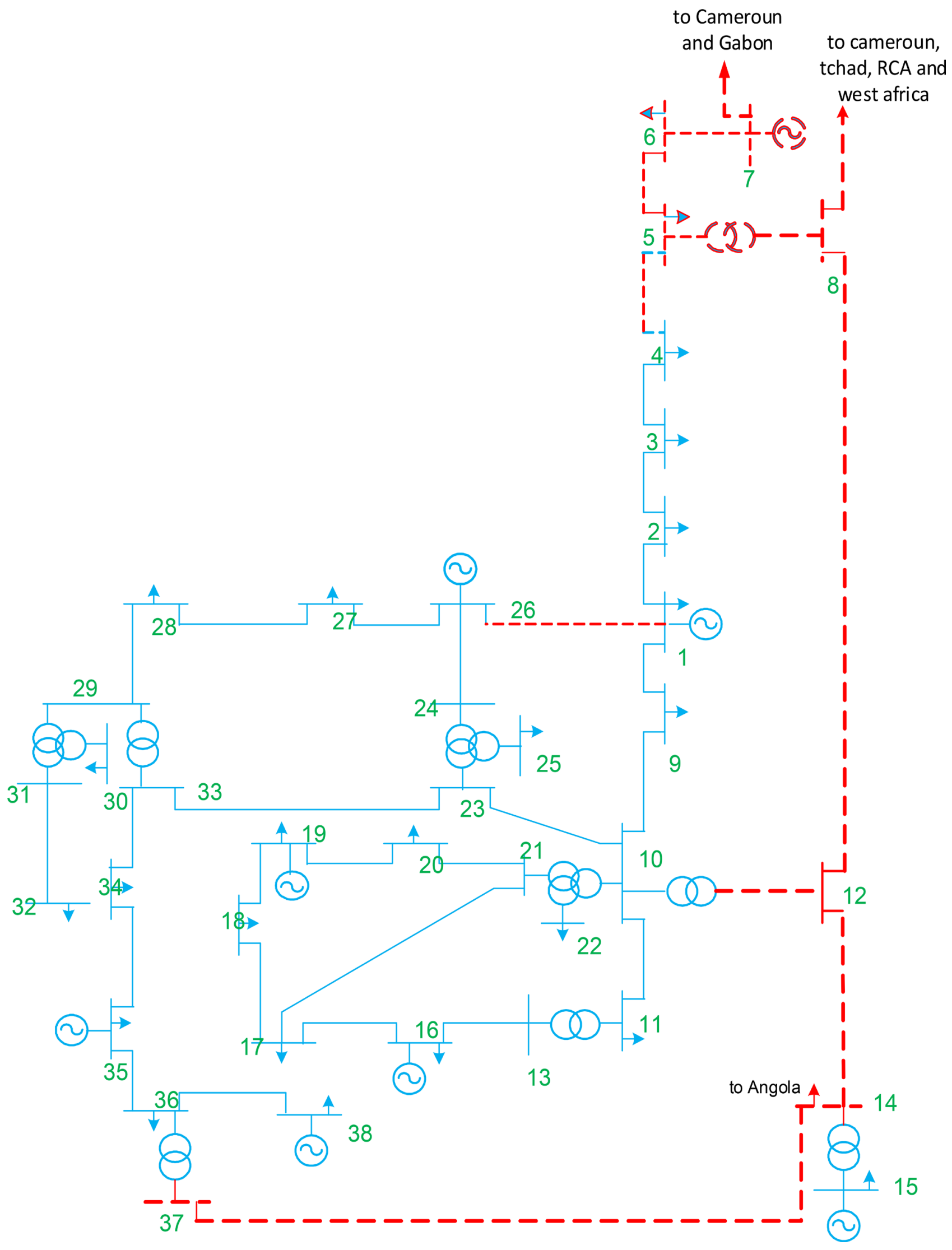

Figure A2. Diagram of the Congolese electricity network integrated into the PEAC. 


\section{Annex 2: Results}

The results of simulations when the Congolese network absorbs electrical energy from the PEAC are presented in Table A1 and Table A2 below.

Table A1. Nodal electrical quantities.

\begin{tabular}{|c|c|c|c|c|c|c|}
\hline Bus & V [p.u.] & phase [rad] & P gen [p.u.] & Q gen [p.u.] & P load [p.u.] & Q load [p.u.] \\
\hline Bus01 & 1.05 & 0 & 0.47086117 & 2.31946878 & 0.4 & 0.248 \\
\hline Bus02 & 1.01829804 & 0.00693108 & $-4.1633 \mathrm{E}-15$ & $-1.8513 \mathrm{E}-14$ & 0.2 & 0.124 \\
\hline Bus03 & 1.00803123 & 0.01264462 & $1.6653 \mathrm{E}-16$ & $4.563 \mathrm{E}-14$ & 0.45 & 0.279 \\
\hline Bus04 & 1.00005618 & 0.02425556 & $3.9968 \mathrm{E}-15$ & $2.8089 \mathrm{E}-14$ & 1 & 0.62 \\
\hline Bus05 & 1 & 0.06615412 & $2.7833 \mathrm{E}-13$ & 3.24823173 & 1 & 0.62 \\
\hline Bus06 & 0.95613086 & 0.1372357 & $1.5081 \mathrm{E}-12$ & $4.1518 \mathrm{E}-12$ & 3 & 1.58 \\
\hline Bus07 & 1.02 & 0.4947754 & 6 & 1.60804912 & 0 & 0 \\
\hline Bus08 & 1.00802162 & 0.18706557 & $6.1617 \mathrm{E}-15$ & $5.4401 \mathrm{E}-15$ & 0.5 & 0.31 \\
\hline Bus09 & 1.02 & 0.33122074 & 1.25 & 0.49294174 & 0 & 0 \\
\hline Bus09 (twt) & 1.00182195 & 0.28518385 & 0 & 0 & 0 & 0 \\
\hline Bus10 & 1.01627756 & 0.32406793 & $3.6082 \mathrm{E}-15$ & $-3.9635 \mathrm{E}-14$ & 0.5 & 0.31 \\
\hline Bus11 & 1.01782609 & 0.3209317 & $-4.6647 \mathrm{E}-17$ & $-7.2319 \mathrm{E}-15$ & 0 & 0 \\
\hline Bus12 & 1.02 & 0.31722659 & 0.15 & 0.15645277 & 0.1 & 0.062 \\
\hline Bus13 & 0.99617294 & 0.25895503 & $-5.6621 \mathrm{E}-15$ & $-1.0547 \mathrm{E}-14$ & 0.5 & 0.31 \\
\hline Bus14 & 0.99956766 & 0.25942345 & $-4.7184 \mathrm{E}-15$ & $5.3083 \mathrm{E}-14$ & 0.15 & 0.093 \\
\hline Bus15 & 1 & 0.25958923 & 0.3 & 0.62695914 & 0.1 & 0.062 \\
\hline Bus16 & 0.99273044 & 0.26483313 & $-2.2204 \mathrm{E}-16$ & $-1.5613 \mathrm{E}-15$ & 0.1 & 0.062 \\
\hline Bus17 & 0.99754489 & 0.29783882 & $-1.119 \mathrm{E}-15$ & $7.1241 \mathrm{E}-15$ & 0 & 0 \\
\hline Bus18 & 0.9900241 & 0.26489371 & $3.3307 \mathrm{E}-16$ & $-5.4956 \mathrm{E}-15$ & 0.5 & 0.31 \\
\hline Bus19 & 1.01299911 & 0.33645666 & $-2.827 \mathrm{E}-14$ & $-1.2622 \mathrm{E}-13$ & 0 & 0 \\
\hline Bus20 & 1.01628828 & 0.34904393 & $-1.1959 \mathrm{E}-15$ & $-2.591 \mathrm{E}-17$ & 0 & 0 \\
\hline Bus20 (twt) & 1.02085201 & 0.3271116 & $6.622 \mathrm{E}-17$ & $-7.2536 \mathrm{E}-15$ & 0 & 0 \\
\hline Bus21 & 1.01796677 & 0.32217383 & $-1.6653 \mathrm{E}-16$ & $-1.4572 \mathrm{E}-15$ & 0.1275 & 0.079 \\
\hline Bus22 & 1.02 & 0.40496601 & 0.72 & -0.06375363 & 0 & 0 \\
\hline Bus23 & 0.98967952 & 0.34808349 & $1.027 \mathrm{E}-14$ & $6.4906 \mathrm{E}-14$ & 0.136 & 0.0843 \\
\hline Bus24 & 0.98952124 & 0.3463491 & $-6.6336 \mathrm{E}-15$ & $-2.6625 \mathrm{E}-14$ & 0.1 & 0.062 \\
\hline Bus25 & 0.9972036 & 0.33028481 & $-1.6781 \mathrm{E}-15$ & $3.5477 \mathrm{E}-15$ & 0 & 0 \\
\hline Bus25 (twt) & 0.9868543 & 0.3140347 & $-4.3354 \mathrm{E}-17$ & $7.0132 \mathrm{E}-15$ & 0 & 0 \\
\hline Bus26 & 0.98918923 & 0.32019292 & $1.3508 \mathrm{E}-16$ & $3.5134 \mathrm{E}-15$ & 0 & 0 \\
\hline Bus27 & 0.9798509 & 0.30715948 & $2.7756 \mathrm{E}-17$ & $-3.1086 \mathrm{E}-15$ & 0.15 & 0.093 \\
\hline Bus28 & 0.98366611 & 0.30839625 & $5.5511 \mathrm{E}-17$ & $-6.7724 \mathrm{E}-15$ & 0.136 & 0.0843 \\
\hline
\end{tabular}


Continued

\begin{tabular}{lcccccc}
\hline Bus29 & 1.01017433 & 0.33867149 & $1.7605 \mathrm{E}-14$ & $1.0967 \mathrm{E}-13$ & 0 & 0 \\
Bus30 & 0.98067267 & 0.38720397 & $1.1102 \mathrm{E}-15$ & $-1.5543 \mathrm{E}-14$ & 2 & 1.24 \\
Bus31 & 1.02 & 0.45565847 & 4.5 & 1.13242573 & 0.02 & 0.0124 \\
Bus32 & 1.01484848 & 0.42271807 & $-6.4393 \mathrm{E}-15$ & $-1.2101 \mathrm{E}-14$ & 1 & 0.62 \\
Bus33 & 1.02 & 0.41105123 & 0.5 & 1.58313381 & 1.5 & 0.93 \\
\hline & Total powers & & $\mathbf{1 3 . 8 9 0 8 6 7 2}$ & $\mathbf{1 1 . 1 0 3 9 0 9 2}$ & $\mathbf{1 3 . 6 6 9 5}$ & $\mathbf{8 . 1 9 5}$ \\
\hline
\end{tabular}

Table A2. Losses in the lines.

\begin{tabular}{|c|c|c|c|c|}
\hline Departure bus & Arrival bus & Line & P Loss [p.u.] & Q Loss [p.u.] \\
\hline Bus01 & Bus02 & 1 & 0.00095869 & 0.02114213 \\
\hline Bus02 & Bus03 & 2 & 0.00103854 & 0.00186922 \\
\hline Bus03 & Bus04 & 3 & 0.00139101 & 0.00584403 \\
\hline Bus04 & Bus05 & 4 & 0.00383957 & 0.07242787 \\
\hline Bus05 & Bus06 & 5 & 0.01563187 & 0.30515945 \\
\hline Bus06 & Bus07 & 6 & 0.10755845 & 2.14274322 \\
\hline Bus01 & Bus08 & 7 & 0.00405612 & 0.00774338 \\
\hline Bus08 & Bus09 & 8 & 0.00240722 & 0.00556323 \\
\hline Bus09 & Bus09 (twt) & 9 & 0.00353321 & 0.04247134 \\
\hline Bus09 & Bus10 & 10 & 0.00121752 & -0.00204284 \\
\hline Bus09 (twt) & Bus17 & 11 & 0.0001662 & -0.00452598 \\
\hline Bus09 (twt) & Bus18 & 12 & -0.00051024 & 0.01389488 \\
\hline Bus09 & Bus19 & 13 & 0.00125379 & 0.00778558 \\
\hline Bus10 & Bus11 & 14 & 0.00011887 & 0.00078011 \\
\hline Bus11 & Bus12 & 15 & $4.7326 \mathrm{E}-05$ & -0.01748126 \\
\hline Bus12 & Bus13 & 16 & 0.00657444 & 0.00298508 \\
\hline Bus13 & Bus14 & 17 & 0.00016016 & -0.00262852 \\
\hline Bus13 & Bus17 & 18 & 0.00247259 & -0.00334371 \\
\hline Bus14 & Bus15 & 19 & $2.9241 \mathrm{E}-05$ & -0.00015254 \\
\hline Bus15 & Bus16 & 20 & 0.00010931 & -0.00314586 \\
\hline Bus16 & Bus17 & 21 & 0.00181131 & -0.00507288 \\
\hline Bus19 & Bus20 (twt) & 22 & 0.00014164 & -0.003857 \\
\hline Bus19 & Bus29 & 23 & 0.0008555 & 0.0021875 \\
\hline Bus20 & Bus20 (twt) & 24 & 0.00073596 & 0.00884665 \\
\hline Bus20 (twt) & Bus21 & 25 & $-3.1371 \mathrm{E}-05$ & 0.00085429 \\
\hline Bus20 & Bus22 & 26 & 0.00701129 & 0.01322077 \\
\hline Bus22 & Bus23 & 27 & 0.00845331 & 0.00931435 \\
\hline
\end{tabular}




\section{Continued}

\begin{tabular}{ccccc}
\hline Bus23 & Bus24 & 28 & 0.00013734 & -0.00360195 \\
Bus24 & Bus25 & 29 & 0.00130122 & 0.00135679 \\
Bus25 & Bus25 (twt) & 30 & 0.00051951 & 0.00624479 \\
Bus25 (twt) & Bus26 & 31 & $3.9582 \mathrm{E}-05$ & -0.00107789 \\
Bus25 (twt) & Bus28 & 32 & $-3.8234 \mathrm{E}-05$ & 0.00104119 \\
Bus25 & Bus29 & 33 & 0.00023725 & 0.00532036 \\
Bus26 & Bus27 & 34 & 0.00039518 & -0.02831079 \\
Bus29 & Bus30 & 35 & 0.00558001 & 0.02304082 \\
Bus30 & Bus31 & 36 & 0.02995397 & 0.20371215 \\
Bus31 & Bus32 & 37 & 0.00973448 & 0.06471416 \\
Bus32 & Bus33 & 38 & 0.00246935 & 0.01388707 \\
\hline
\end{tabular}

The simulation results obtained when the Congolese network injects electrical energy into the PEAC are presented in Table A3 and Table A4.

Table A3. Nodal electrical quantities.

\begin{tabular}{|c|c|c|c|c|c|c|}
\hline Bus & V [p.u.] & phase [rad] & P gen [p.u.] & Q gen [p.u.] & P load [p.u.] & Q load [p.u.] \\
\hline Bus01 & 1.02 & -0.08990637 & 1.2 & 1.65101303 & 0.4 & 0.248 \\
\hline Bus02 & 0.99957515 & -0.08309874 & $-8.0491 \mathrm{E}-16$ & $2.8061 \mathrm{E}-14$ & 0.2 & 0.124 \\
\hline Bus03 & 0.99361502 & -0.07778674 & $7.7716 \mathrm{E}-15$ & $5.2847 \mathrm{E}-14$ & 0.45 & 0.279 \\
\hline Bus04 & 0.99069464 & -0.06650662 & $3.8858 \mathrm{E}-15$ & $3.5749 \mathrm{E}-14$ & 1 & 0.62 \\
\hline Bus05 & 1 & -0.02468612 & $8.058 \mathrm{E}-13$ & 3.15754924 & 1 & 0.62 \\
\hline Bus06 & 0.95613086 & 0.04639546 & $3.9551 \mathrm{E}-12$ & $9.8415 \mathrm{E}-12$ & 3 & 1.58 \\
\hline Bus07 & 1.02 & 0.40393516 & 6 & 1.8925663 & 0 & 0 \\
\hline Bus08 & 1.00573151 & -0.10555159 & $3.8858 \mathrm{E}-15$ & $3.7192 \mathrm{E}-14$ & 0.5 & 0.31 \\
\hline Bus09 & 1 & -0.11084273 & $3.6637 \mathrm{E}-14$ & 14.5824018 & 0 & 0 \\
\hline Bus09 (twt) & 0.98977845 & -0.15844268 & $1.6154 \mathrm{E}-15$ & $-3.8191 \mathrm{E}-15$ & 0 & 0 \\
\hline Bus10 & 0.9726693 & -0.11963459 & $2.1316 \mathrm{E}-14$ & $1.35 \mathrm{E}-13$ & 29 & 15.276 \\
\hline Bus11 & 1.01597592 & 0.02485171 & $-1.1324 \mathrm{E}-13$ & $6.839 \mathrm{E}-13$ & 3 & 1.86 \\
\hline Bus12 & 1.02 & 0.03599956 & 25 & 4.94096046 & 0 & 0 \\
\hline Bus13 & 1.00104374 & -0.11947222 & $-8.9928 \mathrm{E}-15$ & $-3.1364 \mathrm{E}-14$ & 0.5 & 0.31 \\
\hline Bus14 & 1.00928577 & -0.12391194 & $3.1134 \mathrm{E}-15$ & $-3.8778 \mathrm{E}-16$ & 0 & 0 \\
\hline Bus15 & 1.02 & -0.12832385 & 0.15 & 0.59052781 & 0.1 & 0.062 \\
\hline Bus16 & 0.99537043 & -0.19003968 & $-4.6629 \mathrm{E}-15$ & $-4.2411 \mathrm{E}-14$ & 0.5 & 0.31 \\
\hline Bus17 & 0.99949471 & -0.18968446 & $1.2712 \mathrm{E}-13$ & $4.9966 \mathrm{E}-13$ & 0.15 & 0.093 \\
\hline
\end{tabular}




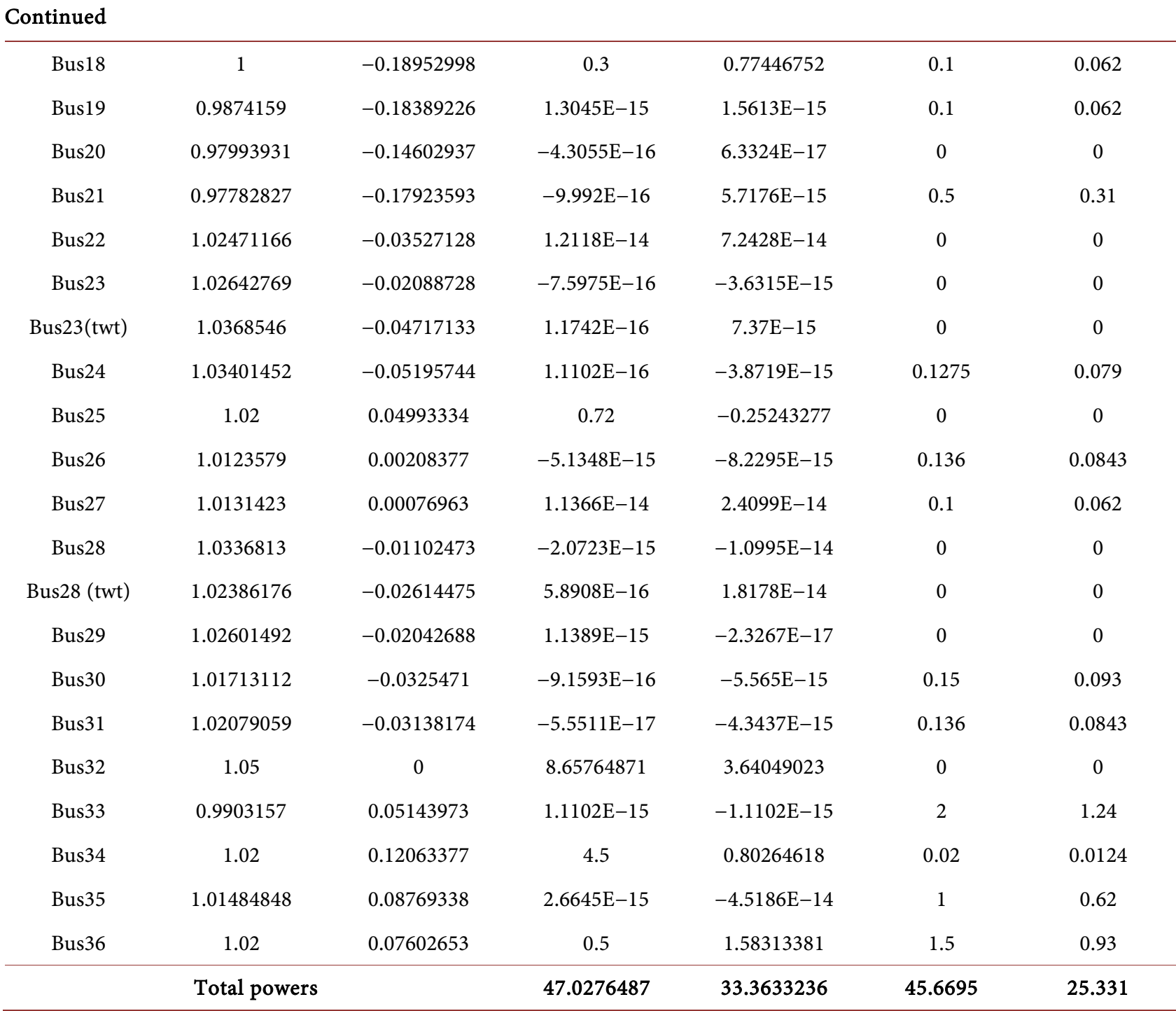

Table A4. Losses in the lines.

\begin{tabular}{ccccc}
\hline Departure bus & Arrival bus & Line & P Loss & Q Loss \\
\hline Bus01 & Bus02 & 1 & 0.00071896 & 0.01562483 \\
Bus02 & Bus03 & 2 & 0.00079833 & 0.0003731 \\
Bus03 & Bus04 & 3 & 0.00127651 & 0.00515473 \\
Bus04 & Bus05 & 4 & 0.00408284 & 0.07744503 \\
Bus05 & Bus06 & 5 & 0.01496751 & 0.29216087 \\
Bus06 & Bus07 & 6 & 0.11033549 & 2.19810752 \\
Bus01 & Bus08 & 7 & 0.00435453 & 0.01023328 \\
Bus08 & Bus09 & 8 & 0.00123606 & 0.00139634 \\
Bus09 & Bus09 (twt) & 9 & 0.0033221 & 0.03993357 \\
Bus09 & Bus10 & 10 & 0.07773839 & 0.51015818 \\
\hline
\end{tabular}




\section{Continued}

\begin{tabular}{|c|c|c|c|c|}
\hline Bus09 & Bus13 & 11 & 0.00137665 & -0.0010526 \\
\hline Bus09 (twt) & Bus20 & 12 & 0.0002295 & -0.00624983 \\
\hline Bus09 (twt) & Bus21 & 13 & -0.00052305 & 0.01424365 \\
\hline Bus09 & Bus22 & 14 & 0.1047277 & 0.71300615 \\
\hline Bus10 & Bus11 & 15 & 0.77102902 & 3.17126108 \\
\hline Bus11 & Bus12 & 16 & 0.0453166 & 0.29739019 \\
\hline Bus13 & Bus14 & 17 & 0.00083061 & 0.0054509 \\
\hline Bus14 & Bus15 & 18 & 0.00033624 & -0.01154928 \\
\hline Bus15 & Bus16 & 19 & 0.00731984 & 0.00448387 \\
\hline Bus16 & Bus17 & 20 & 0.00023371 & -0.00200302 \\
\hline Bus16 & Bus20 & 21 & 0.00349657 & -0.00043103 \\
\hline Bus17 & Bus18 & 22 & $3.8077 \mathrm{E}-05$ & $-7.7779 \mathrm{E}-05$ \\
\hline Bus18 & Bus19 & 23 & 0.00025879 & -0.00186011 \\
\hline Bus19 & Bus20 & 24 & 0.00237188 & -0.00335134 \\
\hline Bus22 & Bus32 & 25 & 0.13016904 & 0.36531299 \\
\hline Bus22 & Bus23 (twt) & 26 & 0.00027764 & -0.00756053 \\
\hline Bus23 & Bus23 (twt) & 27 & 0.00119472 & 0.01436122 \\
\hline Bus23 (twt) & Bus24 & 28 & $-3.0405 \mathrm{E}-05$ & 0.00082798 \\
\hline Bus23 & Bus25 & 29 & 0.0113961 & 0.02636283 \\
\hline Bus25 & Bus26 & 30 & 0.00489291 & 0.0009106 \\
\hline Bus26 & Bus27 & 31 & 0.00011033 & -0.00384938 \\
\hline Bus27 & Bus28 & 32 & 0.00235443 & 0.00319298 \\
\hline Bus28 & Bus28 (twt) & 33 & 0.00047903 & 0.00575817 \\
\hline Bus28 (twt) & Bus29 & 34 & $3.6328 \mathrm{E}-05$ & -0.00098929 \\
\hline Bus28 (twt) & Bus31 & 35 & $-3.5504 \mathrm{E}-05$ & 0.00096684 \\
\hline Bus28 & Bus32 & 36 & 0.00039515 & 0.00886129 \\
\hline Bus29 & Bus30 & 37 & 0.00036439 & -0.03090029 \\
\hline Bus32 & Bus33 & 38 & 0.01099716 & 0.05402413 \\
\hline Bus33 & Bus34 & 39 & 0.02747072 & 0.18659458 \\
\hline Bus34 & Bus35 & 40 & 0.00973448 & 0.06471416 \\
\hline Bus35 & Bus36 & 41 & 0.00246935 & 0.01388707 \\
\hline \multicolumn{3}{|c|}{ Total loss } & 1.35814871 & 8.03232364 \\
\hline
\end{tabular}

